Journal of Mammalogy, Vol. 54, No. 1 (Feb., 1973), pp. 263-266

February 1973

GENERAL NOTES

263

This document is a U.S. government work and

is not subject to copyright in the United States.

PMID: 4705259

\title{
BODY TEMPERATURES OF MANIS GIGANTEA AND MANIS TRICUSPIS
}

Little information has been published with regard to body temperatures of pangolins. Eisentraut (Saugetierk. Mitt., 4:64-67, 1956) provided a few rectal temperatures of Manis tricuspis. Data available on body temperatures, as well as detailed information on other aspects of the biology of pangolins, were summarized by Mohr (Schuppentiere, Die neue Brehm-Bücherei, A. Ziemsen Verlag-Wittenberg Lutherstadt, 99 pp., 1961).

The purpose of this report is to present some additional information on body temperatures and thermal regulatory responses of $M$. gigantea and $M$. tricuspis.

The data presented herein were obtained from studies of pangolins obtained from the

TABLE 1.-Arithmetic means and extremes of body temperatures of pangolins and ambient temperatures recorded during the day.

\begin{tabular}{cccc}
\hline Hours & Manis gigantea & Manis tricuspis & Ambient \\
\hline $0701-0800$ & 33.70 & 29.30 & 26.13 \\
& $(33.0-34.0)$ & $(29.0-29.5$ & $(25.5-27.0)$ \\
$0801-0900$ & 33.80 & 29.00 & 27.28 \\
& $(33.8-33.8)$ & $(29.0-29.0$ & $(25.8-28.0)$ \\
$0901-1000$ & 33.90 & 29.02 & 28.30 \\
$1001-1100$ & $(33.8-34.0)$ & $(28.8-29.5)$ & $(27.8-29.0)$ \\
& 34.00 & 29.66 & 29.01 \\
$1101-1200$ & $(34.0-34.0)$ & $(29.5-30.0)$ & $(28.2-29.5)$ \\
$1201-1300$ & 34.30 & 30.50 & 29.77 \\
& $(34.3-34.3)$ & $(30.5-30.5)$ & $(29.3-30.0)$ \\
$1301-1400$ & 34.50 & 29.90 & 29.45 \\
& $(34.5-34.5)$ & $(29.8-30.0)$ & $(28.8-30.0)$ \\
$1401-1500$ & 34.50 & 30.66 & 29.64 \\
& $(34.5-34.5)$ & $(30.5-31.0$ & $(29.0-30.5)$ \\
$1501-1600$ & 34.50 & 30.50 & 30.00 \\
$1601-1700$ & $(34.5-34.5)$ & $(30.5-30.5)$ & $(29.0-31.0)$ \\
& 34.50 & - & 31.00 \\
$1701-1800$ & $(34.5-34.5)$ & - & $(31.0-31.0)$ \\
& - & 32.00 & 29.80 \\
$1801-1900$ & - & $(32.0-32.0$ & $(29.8-29.5)$ \\
$1901-2000$ & - & - & - \\
& 34.00 & 33.30 & 27.17 \\
& $(34.0-34.0)$ & $(33.3-33.3)$ & $(27.0-27.5)$ \\
& 32.00 & - & 25.80 \\
& $(32.0-32.0)$ & - & $(25.8-25.8)$ \\
\hline
\end{tabular}




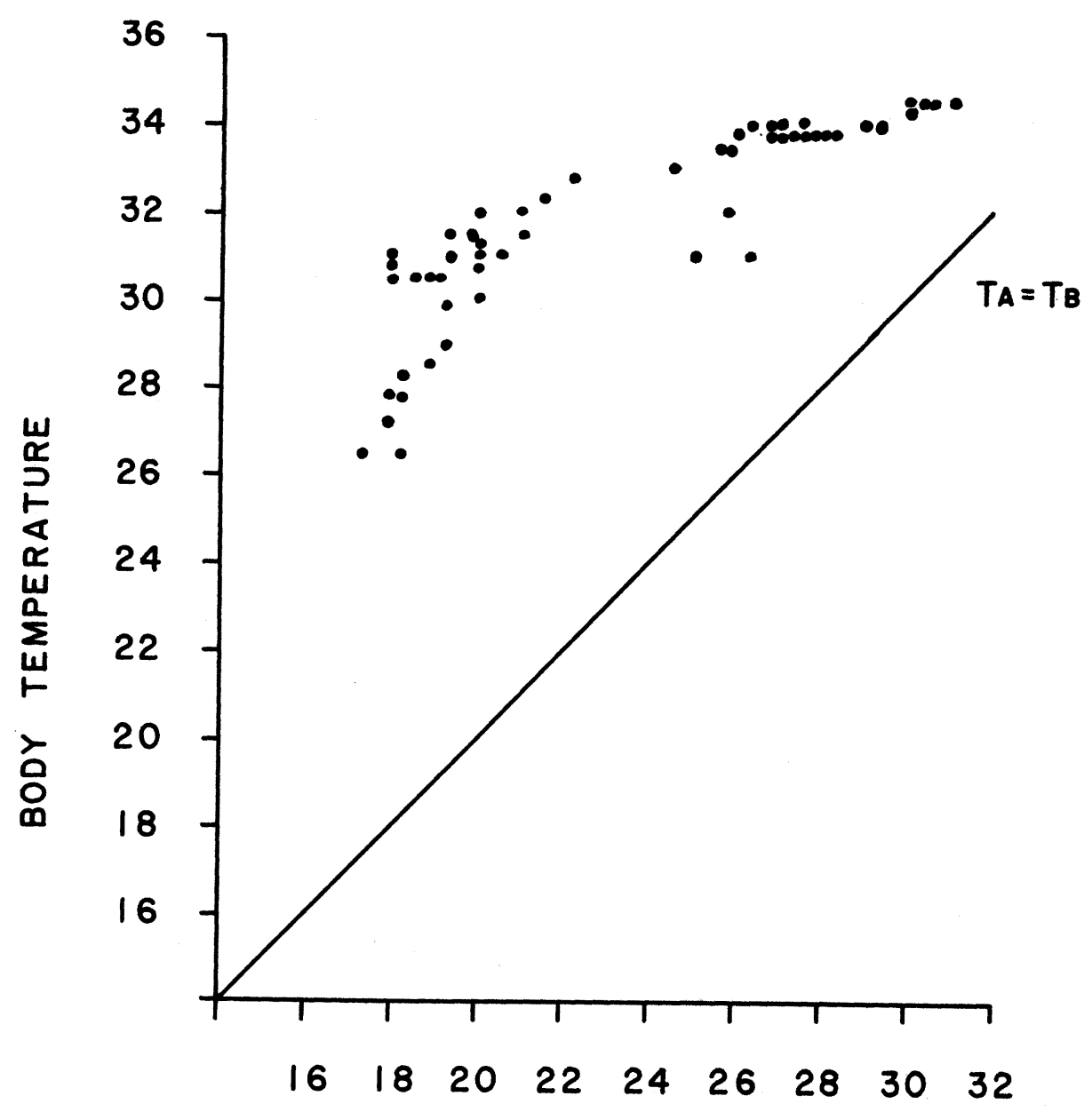

\section{AMBIENT TEMPERATURE}

Fig. 1.-Body temperature of $M$. gigantea in relation to ambient temperature.

following localities in Rio Muni, West Africa: Manis gigantea-Ebengon, $10^{\circ} 27^{\prime} \mathrm{E}$ long, $2^{\circ} 9^{\prime} \mathrm{N}$ lat (male), near Cogo, $9^{\circ} 45^{\prime} \mathrm{E}$ long, $1^{\circ} 15^{\prime} \mathrm{N}$ lat (female); Manis tricuspis-Bata, $9^{\circ} 46^{\prime} \mathrm{E}$ long, $1^{\circ} 52^{\prime} \mathrm{N}$ lat (male), Evuenam, $9^{\circ} 54^{\prime} \mathrm{E}$ long, $1^{\circ} 27^{\prime} \mathrm{N}$ lat (female), near Cogo, $9^{\circ} 45^{\prime} \mathrm{E}$ long, $1^{\circ} 15^{\prime} \mathrm{N}$ lat (female).

Body temperatures of pangolins and ambient temperatures were taken with a YSI thermister thermometer and metal probes. Before each use, the thermister thermometer was calibrated and readings were compared with air temperatures taken with a pocket thermometer and a Taylor maximum-minimum thermometer. All temperatures were recorded in degrees centigrade.

Body temperatures and ambient temperatures were recorded while fasted pangolins were either unrestrained in cages or restrained in baskets and placed in a Stokvis commercial electric refrigerator. To obtain body temperatures, probes were inserted approximately 5 centimeters into the rectum and leads were taped to the tails of the animals. 


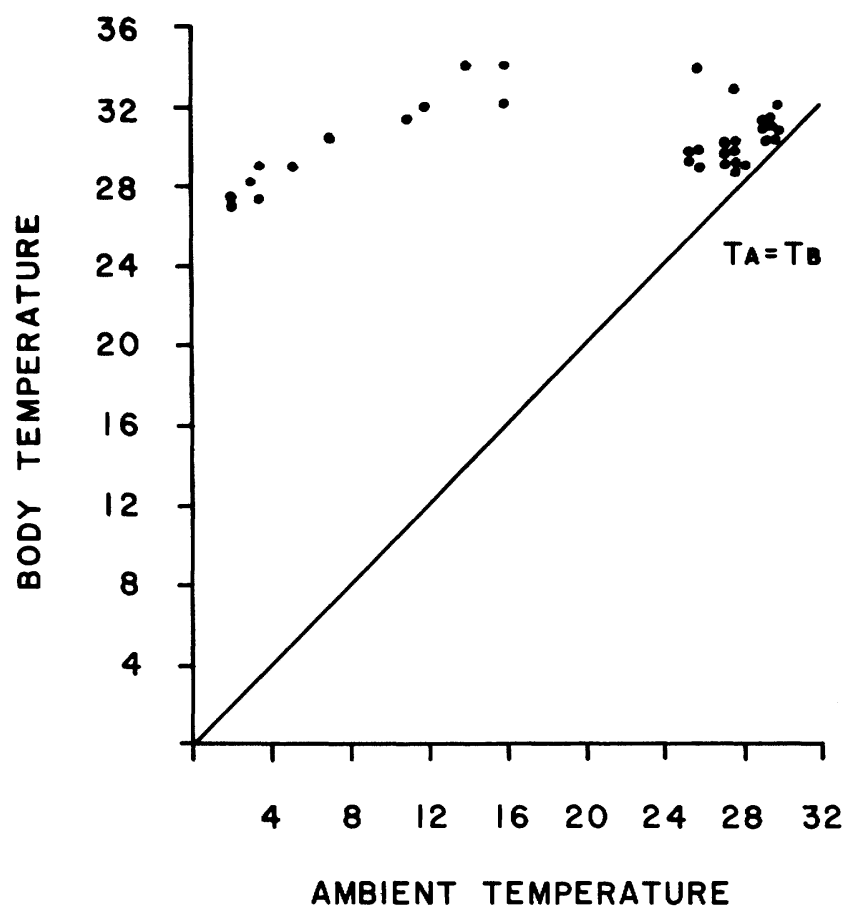

Fig. 2.-Body temperature of $M$. tricuspis in relation to ambient temperature.

Ambient temperatures were taken by probes taped to sides of cages or baskets and positioned about 5 to 10 centimeters from the animals. Body and ambient temperatures were recorded concurrently. Because no apparent differences were detected between the sexes and ages with regard to body temperatures recorded during this study, data for young and adult males and females were combined.

Body temperatures of the animals increased generally during the day (Table 1). Temperatures of $M$. gigantea were more stable than temperatures of $M$. tricuspis; variation in the former was 2.5 degrees (32.0-34.5), but the latter varied by 4.5 degrees (28.8-33.3). Body temperatures of $M$. tricuspis recorded by Eisentraut (op. cit.) were 32.6 degrees at 0600-0800 hours, 33.0 degrees at 1030-1500 hours, 33.04 degrees at 1530-1900 hours, and 33.66 degrees at $2000-2130$ hours.

Body temperatures of $M$. tricuspis reflected activities of the animals. These pangolins moved about occasionally during the day and became very active at about 1800 hours. On the other hand, $M$. gigantea was inactive throughout the day.

The relationships of body temperatures to ambient temperatures in the animals studied are shown in Figs. 1-2. Discrepancies in the amounts of data presented reflect the numbers of animals tested in various ambient temperatures because the temperatures of pangolins not exposed to decreased ambient temperatures are included also in the figures.

Manis gigantea maintained body temperatures of 26.5 to 34.5 degrees in a range of ambient temperatures from 17.0 to 31.0 degrees (Fig. 1). In ambient temperatures below 26.0 degrees, there were variable and sometimes rapid drops in body temperatures. This species exhibited complete recovery upon warming after exposures to ambient temperatures decreased to 16.0 degrees.

Body temperatures of 27.0 to 34.0 degrees were recorded for $M$. tricuspis exposed to ambient temperatures that ranged from 2.0 to 29.8 degrees (Fig. 2). One animal exhibited 
low body temperatures (16.0-24.3 degrees) in ambient temperatures below 10.0 degrees, but this pangolin expired shortly after the test and these data were not plotted in Fig. 2. For the other animals tested in ambient temperatures below 20.0 degrees, there were gradual decreases in body temperatures. Except for the aforementioned death, animals exposed to low ambient temperatures recovered fully upon warming at the termination of tests.

Examination of the limited data available from West African pangolins tested for thermal responses to reduced ambient temperatures revealed that $M$. gigantea and $M$. tricuspis were homeothermic with body temperatures from 26.5 to 34.5 degrees in ambient temperature ranges of 2.0 to 31.0 degrees. However, the body temperatures of pangolins recorded during this study and by Eisentraut (op. cit.) were slightly below the ordinary range of mammalian temperatures.

The data presented herein were obtained while the author was conducting field studies in Rio Muni, West Africa, supported by the National Geographic Society and the National Institutes of Health (FR00164).-CLYDE Jones, Bird and Mammal Laboratories, Bureau of Sport Fisheries and Wildlife, National Museum of Natural History, Washington, D. C. 20560. Accepted 1 September 1972. 